\title{
ANÁLISE INTEGRADA DE DADOS DE SENSORIAMENTO REMOTO, GEOLOGIA E GEOFÍSICA NO ESTUDO DE AQÜÍFERO FRATURADO, LINDÓIA - SP
}

\author{
Vanessa Madrucci ${ }^{1}$, Fabio Taioli ${ }^{2}$ e Carlos César de Araújo $0^{3}$ \\ Recebido em 24 outubro, 2005 / Aceito em 22 dezembro, 2005 \\ Received on October 24, 2005 / Accepted on December 22, 2005
}

\begin{abstract}
Detecting groundwater in fractured aquifers is always a difficult task. This paper presents the detailed study of a fractured aquifer in Lindóia region, São Paulo, Brazil. The study area was selected after a regional study analyzing the favorability for occurrence of groundwater which classified the area as being of excellent groundwater favorability. The study consisted on fractures mapping based on aerial photographs (scale 1:25,000) and geoelectrical survey (vertical electrical sounding and resistivity imaging). The geophysical data was processed, inverted and analyzed by using geological field data, wells data, springs data and fractures mapped using aerial photographs. The results show that it was possible to define favorable locations for the wells and optimize field work.
\end{abstract}

Keywords: fractured aquifer, resistivity, aerial photographs, fractures, geophysical data inversion, integrated data analysis.

RESUMO. Este trabalho apresenta um estudo de detalhe no aqüífero fraturado na região de Lindóia, Estado de São Paulo. A partir do estudo regional de favorabilidade de ocorrência de água subterrânea definiu-se a área de estudo a qual foi mapeada como excelente favorabilidade. 0 estudo de detalhe consistiu no mapeamento de fraturas em fotografias aéreas (escala 1:25.000) e realização de levantamento geofísico de eletrorresistividade (caminhamento elétrico e sondagem elétrica vertical). Realizou-se a inversão dos dados geofísicos e a análise integrada desses dados com os dados geológicos de campo, dados de poços, fontes e fraturas mapeadas em fotografias aéreas. Os resultados mostram que foi possível otimizar os trabalhos de campo com a obtenção de resultados satisfatórios em relação à definição de locais mais favoráveis para a locação de poços.

Palavras-chave: aqüifero cristalino, eletrorresistividade, fotografias aéreas, fraturas, inversão de dados geofísicos, análise integrada de dados.

\footnotetext{
${ }_{1}^{1}$ Centran, (End. Res.) R. Senador Furtado, 39 apto 212, Maracanã, 20270-021 Rio de Janeiro, RJ, Brasil. Tel: (21) 2568-8990; Cel: (21) 9533-8280 -E-mail: madrucci@usp.br

2 Instituto de Geociências - USP, Rua do Lago, 562, Cidade Universitária, 05508-900 São Paulo, SP, Brasil. Tel: (21) 2568-8990 - E-mail: ftaioli@usp.br

${ }^{3}$ ANI - Petrobras, Av. República do Chile, 65 - Centro, 20031-912 Rio de Janeiro, RJ, Brasil. Tel: (21) 3224-9226; Cel: (21) 9689-9897 -E-mail: ccaraujo@petrobras.com.br
} 


\section{INTRODUÇÃo}

Verifica-se a importância das águas subterrâneas para 0 abastecimento da população, indústrias e propriedades rurais. As rochas cristalinas fraturadas apresentam um grande potencial para a acumulação de água, porém para que se obtenha sucesso em perfurações de poços é necessário que se avaliem de modo mais preciso os recursos e as ocorrências dos aqǘf́eros fraturados em relação aos condicionantes geológicos. Métodos geofísicos elétricos são utilizados com sucesso na caracterização de aqüíferos fraturados, com a identificação da espessura do manto de intemperismo, profundidade do topo rochoso, fraturas preenchidas por água e conseqüentemente na determinação de locais para a perfuração de poços (Palacky \& Kadekaru, 1979; Carruthers \& Smith, 1992; Hazell et al., 1992, Gallas, 2000; Gallas, 2003; Vouillamoz et al., 2003).

Considerando-se um mesmo tipo litológico, as fraturas preenchidas por água apresentam um comportamento de baixa resistividade (alta condutividade) em meio a valores de alta resistividade (Gallas, 2000; Gallas, 2003; Vouillamoz et al., 2003). Segundo Gallas (2003), a interpretação prévia de fotografias aéreas é fundamental para o melhor posicionamento da malha dos ensaios geofísicos, de modo que os perfis geofísicos sejam transversais às estruturas identificadas.

Devido à complexidade do aqüífero cristalino, a identificação precisa dos parâmetros de maior influência na infiltração, circulação e armazenamento de água subterrânea não é uma tarefa simples. Na área de estudo, verifica-se a grande variação na produtividade de poços, locados muitas vezes a pequenas distâncias entre si, dentro de uma mesma propriedade, principalmente em empresas mineradoras de água. Isso ocorre porque os poços são locados sem nenhum ou pouco estudo geológico prévio, em função apenas da sua proximidade com outro poço produtivo ou devido aos locais serem de fácil acesso.

Por isso nos levantamentos geofísicos de eletrorresitividade, técnicas de inversão e a análise integrada desses dados com dados de geológicos, de sensoriamento remoto e dados de poços são extremamente importantes para a determinação e confiabilidade dos parâmetros hidrogeológicos. Em terrenos cristalinos, muitas vezes devido a ausência de dados geológicos, de sensoriamento remoto e aerogeofísicos, os perfis geofísicos são dispostos de modo a se interceptar, numa malha quadrática. Além disso, a escassez de dados de poços também dificulta a análise integrada de dados geológicos e geofísicos.

Este trabalho apresenta não somente a aplicação e interpretação de métodos geofísicos de eletrorresistividade para a detecção de aqüíferos fraturados, mas sim uma análise integrada de dados geológicos de campo, dados de poços e fontes, fraturas mapeadas em fotografias aéreas e em campo e dados geofísicos de eletrorresistividade (caminhamento elétrico e sondagem elétrica vertical) e técnicas de inversão de dados geofísicos. A análise integrada de dados permite otimizar os trabalhos de campo, bem como identificar as feições estruturais mais favoráveis à infiltração, circulação e armazenamento de água. Dessa forma obtém-se parâmetros hidrogeológicos confiáveis e definiem-se os locais mais favoráveis para a locação de poços em regiões cristalinas.

\section{ÁREA DE ESTUDO}

A área localiza-se no município de Lindóia, Estado de São Paulo. Esta região se caracteriza pela grande ocorrência de fontes naturais de águas minerais e pela presença de dezenas de empresas mineradoras de água. A escolha desta área foi devido ao mapeamento em escala regional, realizado por Madrucci (2004) e Madrucci \& Taioli (2004), que definiu a região como de excelente favorabilidade à ocorrência de água subterrânea (Figura 1).

Madrucci (2004) realizou análises de favorabilidade para ocorrência de água subterrânea utilizando dois métodos: conduzido pelo conhecimento (Bonham-Carter, 1994) e conduzido pelos dados (Bonham-Carter, 1994). Os critérios utilizados foram lineamentos estruturais (proximidade, intersecção e densidade), morfoestruturas, isofreqüência de zonas de juntas, litologia (tipo litológico e proximidade com contatos geológicos), morfologia, pedologia e declividade. Detalhes sobre a definição dos pesos atribuídos aos parâmetros prospectivos e as análises de favorabilidade são apresentados em Madrucci (2004) e Madrucci \& Taioli (2004).

A área de estudo abrange aproximadamente $2 \mathrm{~km}^{2}$ e nela estão inseridas três ocorrências de nascentes e instalados cinco poços artesianos.

A área é constituída por rochas do embasamento cristalino cuja idade varia do Paleoproterozóico ao Neoproterozóico. A região sofreu uma evolução geológica policíclica que modificou as rochas de origem por metamorfismo, cisalhamento, migmatização e intrusões ígneas.

Regionalmente a área está inserida num domínio de zonas de cisalhamento dúctil a dúctil-rúptil (pré-cambrianas), de direção regional NE-SW. Na área de estudo localiza-se a zona de cisaIhamento Monte Sião (de caráter transcorrente dextral). No município de Lindóia predominam a noroeste desta zona de cisalhamento exposições de rochas pertencentes ao Complexo Itapira 


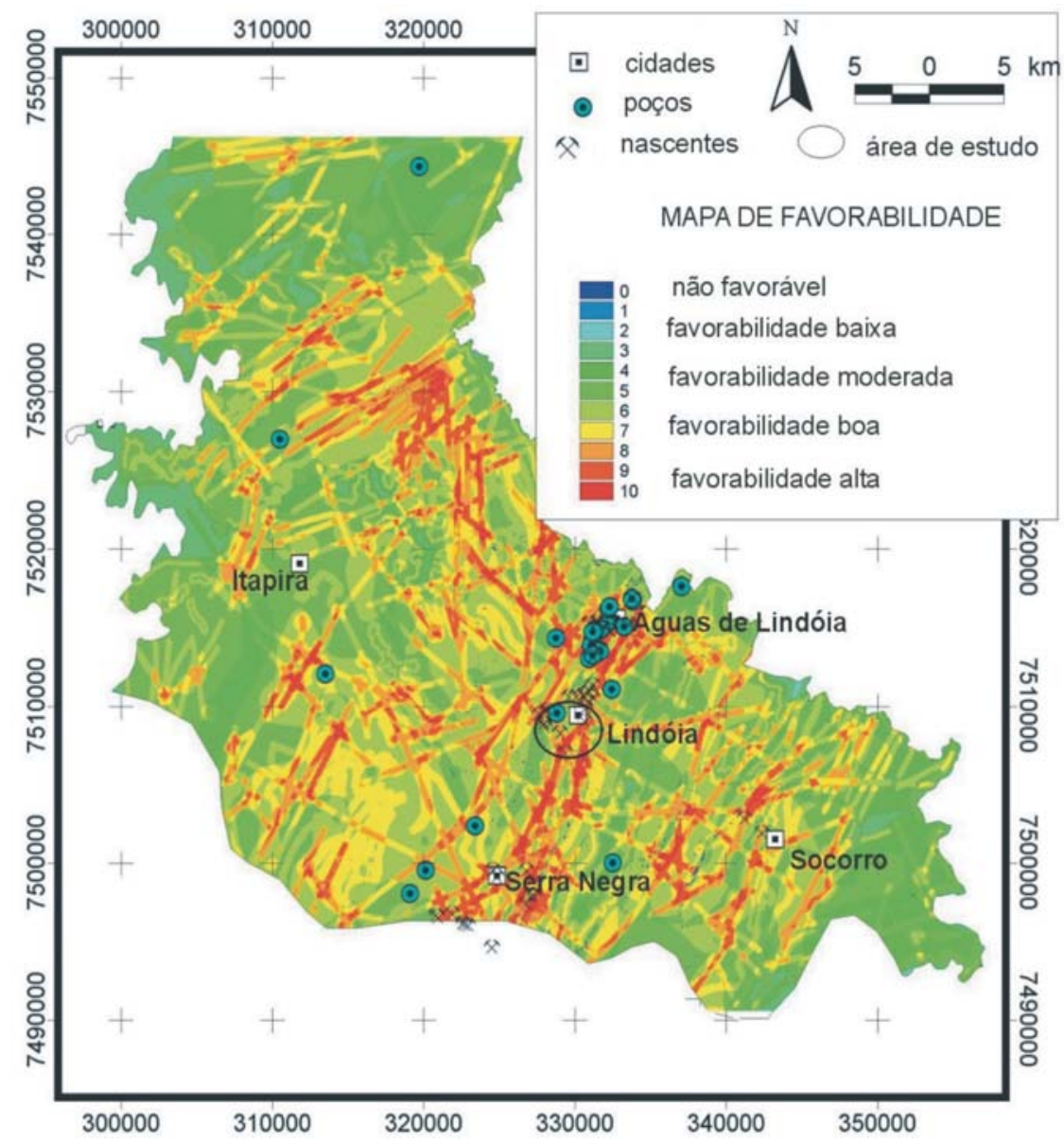

Figura 1 - Mapa de favorabilidade de ocorrência de água subterrânea e delimitação da área de estudo.

(Neoprotezóico), representado por gnaisses e migmatitos, muitas vezes intercalados com xistos, quartzitos e rochas miloníticas, e ao sudeste desta zona de cisalhamento, predominam rochas pertencentes ao Complexo Amparo (Paleoprotezóico), representado por gnaisse, migmatitos, quartzito e intercalações de gnaisse e migmatito, gnaisse e anfibolito (Figura 2).

As rochas dessa região apresentam-se intensamente tectonizadas, com a presença de foliação metamórfica, com proeminente bandamento deformacional e composicional. Além disso, essa região é caracterizada por intenso fraturamento resultante das reativações das linhas de fraqueza crustal pré-cambrianas por esforços tectônicos posteriores. Por conseqüência, essas rochas possuem alta densidade de superfícies planares que, por se constituírem em planos de fraqueza e descontinuidades estruturais características, as tornam propícias à infiltração, circulação e armazenamento de água, com potencial para a existência de bons aqüiferos subterrâneos (CPRM, 2002).
A direção de máximo esforço compressivo (pré-cambriana) é E-W e a direção da zona de cisalhamento principal está em torno de N45E $(=Y)$. Observa-se na área um padrão anastomosado da zona de cisalhamento principal, influenciado pela zona de cisalhamento secundária em torno de N20E ( $P$ - Riedel) e em torno de N60E ( $=R$-Riedel). As direções $X$ (Riedel) e $R^{\prime}$ (Riedel) correspondem a N10W e N60W respectivamente.

De acordo com os dados obtidos nas proximidades das nascentes, tais como foliação milonítica, xistosidade e direções de fraturas, é possivel correlacionar as direções de fraturamento com as feições dúcteis e dúcteis-rúpteis das zonas de cisalhamento transcorrentes Pré-Cambrianas.

Yoshinaga (1990) realizou análises isotópicas nas águas das nascentes da região e concluiu que estas águas são misturas de águas mais superficiais com águas mais profundas que ali emergem. 0 local das nascentes é caracterizado pela topografia acidentada. Ocorrem em fraturas de gnaisses migmatíticos com 


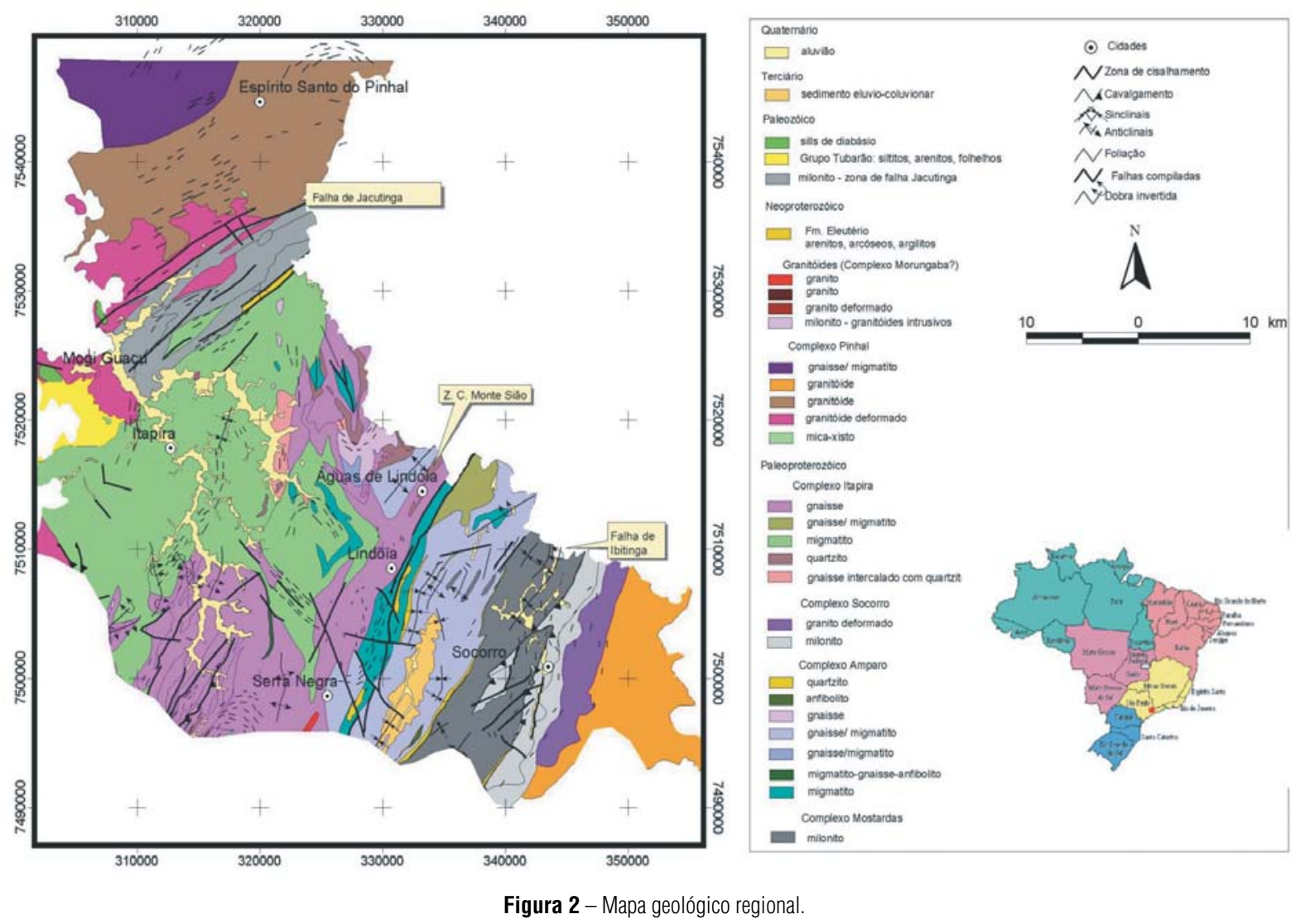

veios de quartzo cortando a foliação, pertencentes ao Complexo Itapira. A surgência da água ocorre em fraturas paralelas ao plano de foliação da rocha. As medidas de foliação obtidas nas fontes foram:

- Fonte São Jorge: N62E/88 NW, N58E/85 SE (R).

- Fonte Santa Rita: N18E/80NW (P), N30E/65SE (P)

- Fonte José Cremasco: N16E/89 SE (P), N14E/85NW (P)

\section{MATERIAIS}

Foram utilizados os seguintes materiais:

a) Cartas topográficas digitalizadas (escala 1:50.000).

b) Mapa de lineamentos estruturais elaborado a partir da interpretação do produto integrado ETM+aeromagnetometria (Madrucci et al., 2003). 0 mapa de lineamentos estruturais possui elevada importância para 0 mapeamento de áreas mais deformadas/fraturadas. 0 que diferencia o mapa utilizado neste trabalho de outros apresentados na literatura é que este foi interpretado levando-se em consideração não somente os elementos texturais da imagem de satélite, mas também as altas respostas magnetométricas. Dessa forma, podem ser identificadas estruturas que não aparecem na imagem de satélite devido ao azimute de iluminação solar (Madrucci et al., 2003).

c) Dados de poços e ocorrências de fontes: esses dados foram cadastrados e inseridos num banco de dados georreferenciado. Os dados de ocorrências de fontes foram adquiridos em etapa de campo e os dados de poços foram adquiridos junto a Minergeo, CPRM e etapa de campo.

Os dados de poços (descrição litológica) são extremamente importantes para a calibração do modelo geofísico. Além disso, os dados de capacidade especíitica dos poços são utilizados como uma medida para avaliar a produtividade do poço e conseqüentemente 0 potencial do aqüífero. Porém, muitas vezes não se obtém esses dados com o detalhamento necessário para este tipo de estudo. 
As ocorrências de fontes têm sua principal importância associada com a possibilidade de mapear as fraturas por onde se verifica a surgência de água. A maior dificuldade relacionada com este tipo de dado é que nem sempre na área de interesse ocorrem nascentes e quando ocorrem, existe a necessidade de intenso trabalho de campo, associado com a permissão da visita nas mineradoras, uma vez que estes locais são muito protegidos.

d) Dados geológicos de campo na forma de descrições litológicas e medidas estruturais.

e) Fotografias aéreas (escala 1:25.000), referentes ao Levantamento de Regiões Cafeeiras, IBC/SA de 1972 (região de Lindóia), emprestadas pelo Instituto Geológico/SMA-SP.

f) Equipamentos: nos levantamentos de eletrorresistividade utilizou-se o resistivímetro Terrameter, modelo SAS 300B, fabricado pela empresa sueca ABEM. Para a melhoria da razão sinal/ruído, utilizou-se um módulo-acessório denominado booster, que possibilita o aumento da potência do equipamento. Como acessórios, utilizaram-se fios de conexão, trenas não metálicas e eletrodos metálicos para 0 envio de corrente e leitura do potencial.

\section{MÉTODOS}

\section{Mapeamento de fraturas nas fotografias aéreas}

Foram interpretados os elementos texturais de relevo e drenagem, com ênfase às quebras negativas de relevo e à estruturação da rede de drenagem (Soares \& Fiori, 1976). As zonas de fraturamento constituem zonas de desenvolvimento preferencial de linhas de drenagem retilíneas. Interpretam-se como traços de fratura quando estabelecidos sobre faixas de concentração de fraturamentos. Os traços de fratura correspondem a zonas de concentração de juntas. Zonas homólogas com maior densidade de traços de fratura refletem rochas de maior grau de ruptibilidade.

No estudo de água subterrânea em terreno cristalino, é importante identificar estas regiões mais fraturadas, pois estas são mais favoráveis à infiltração, circulação e armazenamento de água.

Após o mapeamento das fraturas todas as informações foram integradas em um banco de dados georreferenciado em um sistema de informação geográfica (SIG).

\section{Definição dos perfis geofísicos de caminhamento elétrico e locais para a realização das SEVs}

Com base nas fraturas mapeadas o caminhamento é feito de modo a cruzar ortogonalmente as estruturas geológicas para caracterizar a área de interesse.

\section{Realização dos levantamentos geofísicos de eletror- resistividade}

\section{a) Fundamentação Teórica}

0 método da eletrorresistividade permite obter de forma indireta 0 valor de resistividade elétrica ( $\rho$ ) dos materiais geológicos em subsuperfície. Detalhes acerca da execução desta metodologia encontram-se em Orellana (1972), Keller \& Frischknecht (1977), Telford et al. (1990) entre outros. Nesta metodologia podem ser adotadas duas técnicas de aquisição de campo: a sondagem elétrica vertical (SEV) e o caminhamento elétrico (CE).

\section{- Sondagem Elétrica Vertical (SEV)}

A Sondagem Elétrica Vertical (SEV) investiga as variações de resistividade elétrica com a profundidade, abaixo do ponto de interesse, isto é, investiga variações verticais em subsuperfície. As medidas são efetuadas através de um arranjo composto por quatro eletrodos, dispostos simetricamente em relação ao ponto investigado, o centro do arranjo. Neste trabalho utilizou-se 0 arranjo Schlumberger, onde os eletrodos de potencial (M e N) permanecem próximos a este ponto enquanto os de corrente (A e B) são progressivamente afastados a cada leitura efetuada. À medida que se aumenta 0 espaçamento $A B$, maior será 0 volume amostrado em subsuperfície e, portanto, maiores serão as profundidades investigadas.

Realizaram-se duas SEVs e estabeleceu-se o posicionamento destas de modo que a abertura máxima dos eletrodos de corrente (A e B) estivesse sempre em condições de pouca variação topográfica e ao longo de uma linha reta. Cabe ressaltar que a resistividade determinada é um valor aparente, resultado da contribuição de todo o pacote investigado, geralmente heterogêneo. A interpretação dos dados fornece um modelo geoelétrico do ponto investigado, constituído por camadas plano paralelas, cada qual apresentando uma espessura com 0 respectivo valor de resistividade elétrica verdadeira. Detalhes sobre a fundamentação do método de sondagem elétrica vertical podem ser encontrados em Keller \& Frischknecht (1977), Gallas (2000) e Madrucci (2004).

\section{- Caminhamento Elétrico (CE)}

0 caminhamento elétrico, ao contrário da SEV, tem como objetivo a investigação horizontal a uma ou várias profundidades aproximadamente constantes com medidas efetuadas ao longo de perfis. Tem por objetivo a definição das variações laterais da resistividade em subsuperfície, encontrando grande aplicação no mapeamento de contatos geológicos, identificação de zonas de falhas e fra- 
turas, mapeamento de plumas de contaminação e estruturas ou corpos representados por uma heterogeneidade lateral de resistividade.

Os arranjos de campo utilizados para execução desta técnica são bastante variados. Neste trabalho utilizou-se 0 arranjo dipolodipolo. Segundo Gallas (2000), a grande vantagem da utilização deste arranjo é o fato de se tratar de um arranjo simétrico, sendo mais fácil a interpretação de uma pseudo-seção, principalmente para se determinar com segurança a posição de uma anomalia. Neste arranjo, o quadripolo é alinhado ao longo do perfil, detaIhes sobre a técnica de caminhamento elétrico podem ser encontrados em Keller \& Frischknecht (1977), Gallas (2000), Madrucci (2004), entre outros. Neste trabalho o espaçamento entre 0 dipolo $(x=A B=M N)$ foi definido como $30 \mathrm{~m}$, com 5 níveis de investigação em profundidade. Realizaram-se três perfis de caminhamento elétrico.

Como resultado, os dados são plotados e interpolados, gerando uma pseudo-seção de resistividade aparente, utilizada na interpretação. As pseudo-seções são representações úteis para a interpretação dos dados, porém não devem ser consideradas imagens verdadeiras da subsuperfície, pois a profundidade de investigação não depende unicamente da configuração geométrica do arranjo utilizado, mas também dos contrastes de resistividade das litologias em subsuperfície. Por isso, estas não são as verdadeiras profundidades de investigação e nem suas resistividades reais, sendo denominadas de pseudo-seções (Hallof, 1957 apud Edwards, 1977). A interpretação de anomalias é geralmente feita de forma qualitativa ou semi-qualitativa, ou utilizandose programas para inversão dos dados e geração de modelos geoelétricos.

\section{b) Levantamento de campo}

0 caminhamento elétrico 1 foi realizado na rodovia Lindóia - Itapira. Possui direção aproximadamente E-W e 38 estações de medidas eqüidistantes de $30 \mathrm{~m}$. Esse perfil teve início na porção W (estaca 0) e foi finalizado na estaca 37 (porção E). A SEV foi realizada na estaca 14 , com abertura máxima entre eletrodos de corrente igual a $300 \mathrm{~m}(A B / 2=150 \mathrm{~m})$.

0 caminhamento elétrico 2 foi realizado na propriedade da Mineração Cremasco. Possui direção aproximadamente E-W e é praticamente paralelo ao perfil 1. É definido por 22 estações de medidas eqüidistantes de $30 \mathrm{~m}$. Esse perfil geofísico teve início na porção $\mathrm{E}$ (estaca 0) e finalizou na estaca 21 (porção W). A SEV foi realizada na estaca 16, com abertura máxima entre eletrodos de corrente igual a $80 \mathrm{~m}(A B / 2=40 \mathrm{~m})$.
0 caminhamento elétrico 3 foi realizado na propriedade da Mineração Cremasco. Possui direção aproximadamente NE-SW, definido por 45 estações de medidas eqüidistantes de $30 \mathrm{~m}$. Esse perfil geofísico teve início na porção SW (estaca 0) e foi finalizado na estaca 44 (porção NE).

0 posicionamento de todas as estações (estacas) foi obtido por intermédio de GPS.

\section{INVERSÃO DOS DADOS GEOFÍSICOS}

0 método de inversão consiste na determinação de um modelo bi-dimensional (2-D) de resistividade a partir do conhecimento da geologia local e dos dados obtidos nos levantamentos elétricos de campo. Neste trabalho utilizou-se o programa RESIXIP (Pelton et al., 1978), para a inversão dos dados da SEV e o programa RES 2D INV (Geotomo Software, 2003) para a inversão dos dados do CE.

0 modelo 2-D usado no programa RES 2D INV divide a subsuperfície num número de blocos retangulares, sendo 0 arranjo dos blocos definido pela distribuição dos dados na pseudoseção. 0 programa determina a resistividade dos blocos retangulares que apresentarão uma pseudo-seção de resistividade aparente que ajusta as medidas realizadas.

A rotina de inversão utiliza uma técnica de otimização denominada de "smoothness-constrained least-squares" (GrootHedlin \& Constable, 1990; Sasaki, 1992). Esta otimização procura reduzir a diferença entre os valores de resistividade aparente calculados e os medidos em campo, ajustando a resistividade do modelo de blocos. A medida desta diferença é dada pelo "root mean squared (RMS) error" (Loke \& Barker, 1996).

Além da necessidade da inversão dos dados de eletrorresistividade para uma interpretação mais condizente com a realidade, Fox et al. (1980) apresentam resultados da influência da topografia nas anomalias de resistividade do arranjo dipolo-dipolo e mostram que a modelagem por elementos finitos soluciona 0 problema da topografia. 0 programa de inversão utilizado neste trabalho possui um módulo de correção topográfica que utiliza a técnica dos elementos finitos.

\section{RESULTADOS E DISCUSSÕES}

\section{Fotointerpretação}

As fraturas mapeadas a partir das fotografias aéreas possuem mergulho vertical a sub-vertical com as orientações preferenciais: N60-70E, N40-60W, N40-50E, N70-80E, N20-30E, E-W e N-S. A Figura 3 apresenta a fotografia aérea, com os lineamentos fotointerpretados como zonas de cisalhamento, as fraturas mapea- 


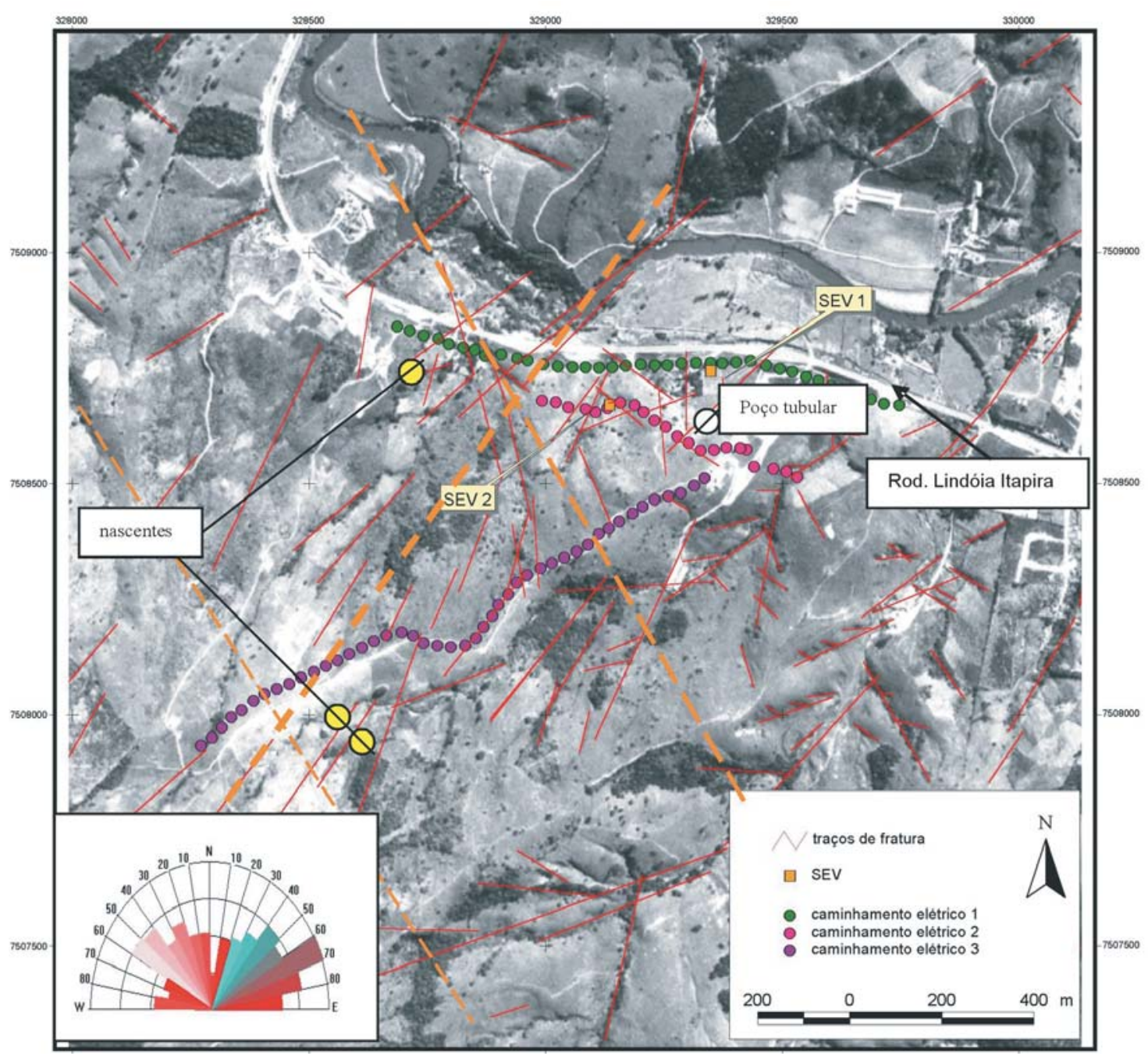

Figura 3 - Fotografia aérea (escala 1:25.000) da área: fraturas mapeadas, estacas dos caminhamentos elétricos e locais das SEVs. Os traços laranja pontilhados são os lineamentos fotointerpretados do produto integrado ETM-MAG que correspondem às zonas de cisalhamento. Rosetas das direções das fraturas interpretadas.

das, os locais onde foram realizadas as SEVs e os caminhamentos elétricos e 0 gráfico de rosetas das direções das fraturas fotointerpretadas.

\section{Levantamento Geofísico de Eletrorresistividade}

A Figura 4 apresenta o resultado da inversão dos dados da SEV-1. 0 gráfico (AB/2 $\times$ resistividade aparente) apresenta os dados de campo (pontos vermelhos) sobrepostos a uma curva contínua que equivale à resposta do modelo geoelétrico calculado (em termos de resistividade verdadeira, espessura e profundidade do topo da camada). A linha pontilhada representa o modelo de resistividade das camadas. 0 ajuste obtido (diferença entre 0 valor medido e calculado a partir do modelo) pode ser avaliado através de um erro de mínimos quadrados (RMS error) também apresentado na Figura 4.

Identificaram-se 5 camadas geoelétricas, sendo que as camadas 1 e 2 podem ser consideradas como uma única camada em função da camada 1 ser uma cobertura muito superficial $e$ de pequena espessura $(1 \mathrm{~m})$. As camadas $1 \mathrm{e} 2$ representam uma cobertura superficial/solo seco, apresentam espessura de 4,4 metros e valores de resistividade próximo de $1.000 \Omega$.m. A camada 3 trata-se de um solo mais saturado $(613 \Omega . \mathrm{m})$ com profundidade de sua base em torno de 16,5 m e espessura $12,1 \mathrm{~m}$. A camada 4 foi interpretada como rocha alterada, com resistividade

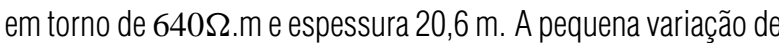


SEV - 1
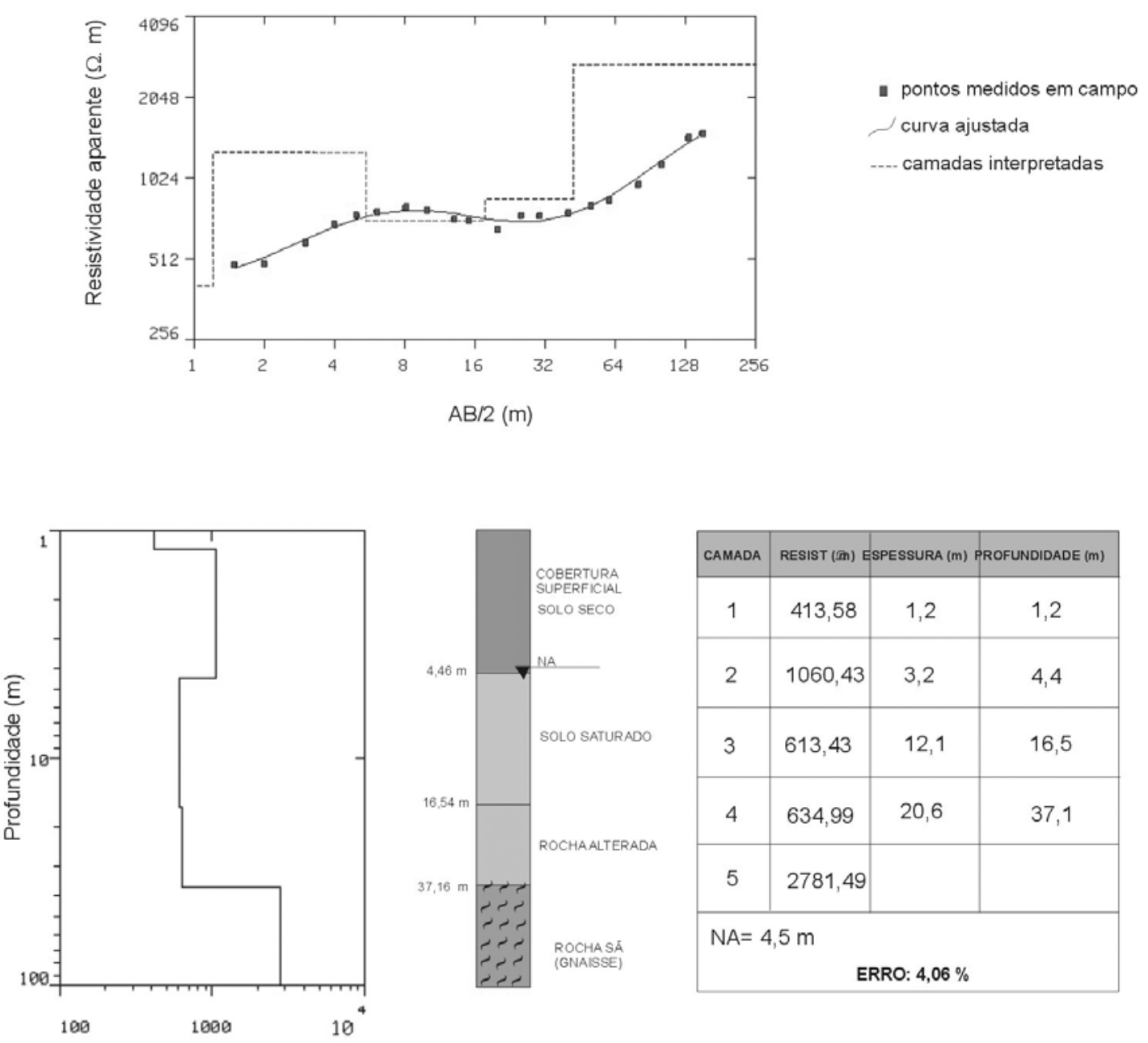

\begin{tabular}{|c|c|c|c|}
\hline CAMADA & RESIST (m) & ESPESSURA $(\mathrm{m})$ & PROFUNDIDADE $(\mathrm{m})$ \\
\hline 1 & 413,58 & 1,2 & 1,2 \\
\hline 2 & 1060,43 & 3,2 & 4,4 \\
\hline 3 & 613,43 & 12,1 & 16,5 \\
\hline 4 & 634,99 & 20,6 & 37,1 \\
\hline 5 & 2781,49 & & \\
\hline NA= 4,5 $\mathrm{m}$ & \\
\end{tabular}

Resistividade $(\Omega m)$

Figura 4 - Resultados da Inversão dos dados da SEV 1.

resistividade entre as camadas 3 e 4 é devida a composição semeIhante, bem como a presença de água em seus interstícios. Além disso, os dados de poços na região auxiliaram na identificação destas duas camadas. A camada 5 representa 0 topo da rocha sã, está a 37 metros de profundidade com resistividade em torno de

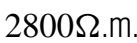

A Figura 5 apresenta a pseudo-seção de resistividade aparente, referente ao CE1 (seção superior) e o perfil resultante da inversão dos dados, incluindo correção topográfica (seção inferior). Nesta seção está representada também a SEV-1.

Como pode ser observado (Figura 5) o topo da rocha sã (no local da SEV-1) localiza-se a 37 metros de profundidade. A partir deste dado é possível inferir a profundidade do topo rochoso para toda a seção, com base no alto valor de resistividade (em torno de $2800 \Omega$.m) que indica a presença de rocha sã. Analisando-se 0 perfil (Figura 5), nota-se claramente algumas variações de resistividade (baixas resistividades em torno de $150 \Omega$.m) no meio de pacotes com resistividade elevada $(1.800 \Omega$.m). Esta informação pode indicar a presença de zonas fraturadas, as quais devem estar preenchidas por água.

A Figura 6 apresenta 0 resultado da inversão dos dados da SEV-2. 0 gráfico (AB/2 $\times$ resistividade aparente) apresenta os dados de campo (pontos vermelhos) sobrepostos a uma curva contínua que equivale à resposta do modelo geoelétrico calcu- 


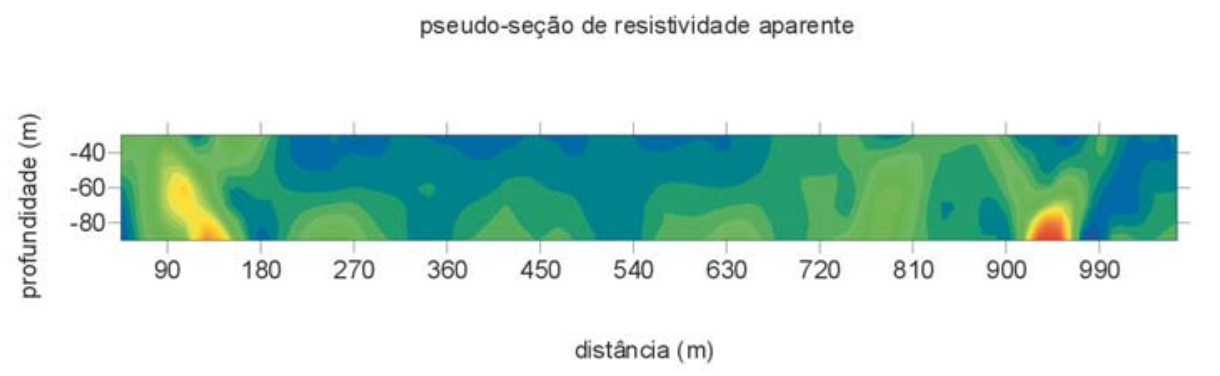

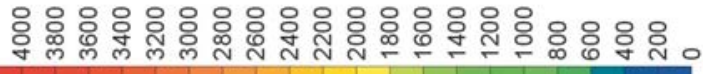
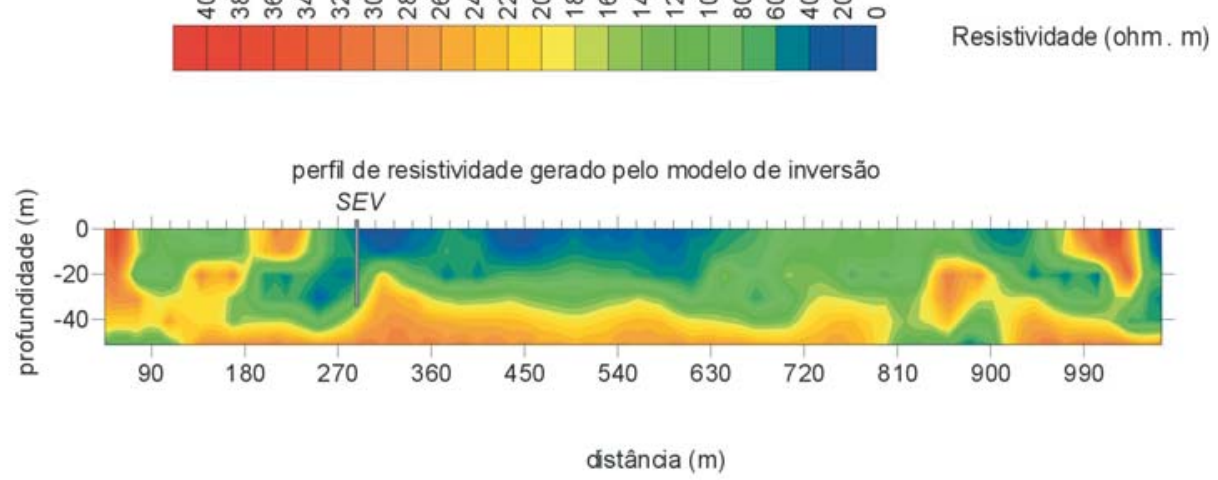

ERRO: $17 \%$

Figura 5 - Pseudo-seção de resistividade aparente e perfil de resistividade gerado pelo modelo de inversão.

lado. A linha pontilhada representa o modelo de resistividade das camadas. 0 ajuste obtido pode ser avaliado através de um erro de mínimos quadrados, também apresentado na Figura 6 .

Identificaram-se 4 camadas geoelétricas, a camada 1 representa uma cobertura superficial/solo seco, apresentando uma profundidade de 0,6 metros e valor de resistividade próximo de $900 \Omega$.m. A camada 2 trata-se de um solo mais saturado $(150 \Omega$.m) com profundidade em torno de $8 \mathrm{~m}$ e espessura $7 \mathrm{~m}$. A camada 3 foi interpretada como rocha alterada (saprolito), com resistividade em torno de $200 \Omega$. $\mathrm{m}$ e espessura de $7 \mathrm{~m}$. A pequena variação de resistividade entre as camadas 2 e 3 é devida a composição semelhante, bem como a presença de água em seus interstícios. Além disso, os dados de poços na região auxiliaram na identificação destas duas camadas. A camada 4 representa 0 topo do embasamento e está a $15 \mathrm{~m}$ de profundidade com resistividade em torno de $4000 \Omega . m$.

Devido à existência de dois poços cadastrados nas proximidades da SEV, com perfis construtivos e litológicos, foi possível "calibrar" a interpretação desta SEV, conforme mostra a Figura 6.

A Figura 7 apresenta a pseudo-seção de resistividade aparente (seção superior) e o perfil resultante da inversão dos dados, incluindo correção topográfica (seção inferior). Nesta seção está representada também a SEV-3.

Como pode ser observado (Figura 7) o topo da rocha sã (no local da SEV-1) Iocaliza-se a 15 metros de profundidade. A partir deste dado é possível inferir a profundidade do topo rochoso para toda a seção, com base no dado de resistividade da rocha sã (a partir de $1800 \Omega$.m).

Analisando-se o perfil (Figura 7) nota-se claramente algumas variações de resistividade (baixas resistividades em torno de $600 \Omega$.m) no meio de pacotes com resistividade elevada $(1600 \Omega$.m). Esta informaçãao pode indicar a presença de zonas fraturadas, as quais devem conter água.

A Figura 8 apresenta a pseudo-seção de resistividade aparente referente ao CE3 (seção superior) e o perfil resultante da inversão dos dados, incluindo correção topográfica (seção intermediária). A seção inferior é um detalhe ampliado da seção intermediária e corresponde também ao dado invertido.

Como pode ser observado (Figura 8) o topo rochoso localizase a aproximadamente 10 metros de profundidade (resistividade da rocha sã a partir de $1800 \Omega$.m).

Analisando-se o perfil (Figura 8), nota-se claramente algu- 


\section{SEV - 2}



- pontos medidos em campo

curva ajustada

.... camadas interpretadas
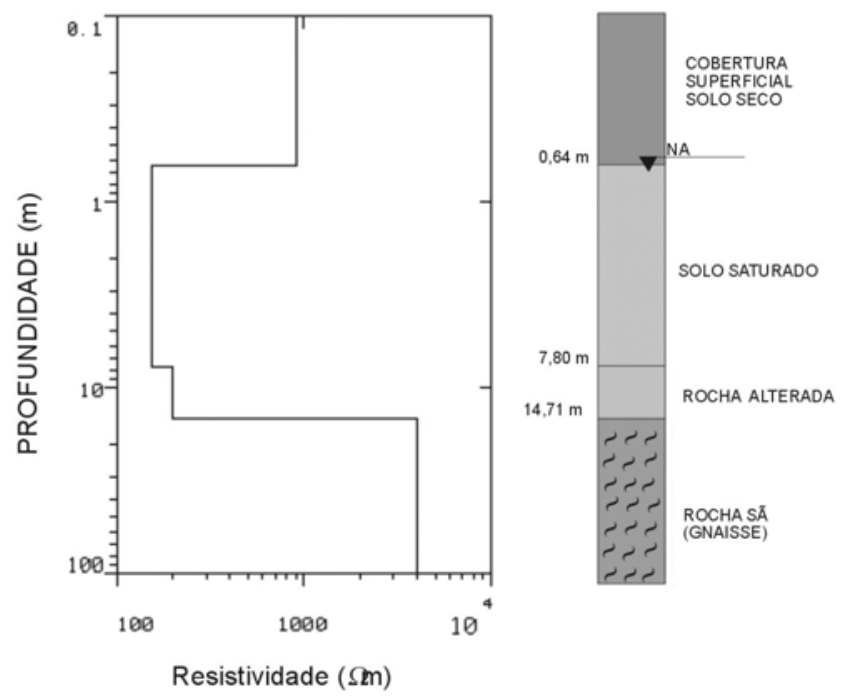

\begin{tabular}{|c|c|c|c|}
\hline CAMADA & RESIST (m) ESPESSURA (m) PROFUNDIDADE (m) \\
\hline 1 & 914 & 0,64 & 0,64 \\
\hline 2 & 153,91 & 7,16 & 7,80 \\
\hline 3 & 199,95 & 6,91 & 14,71 \\
\hline 4 & 3961,91 & \\
\hline & \\
NA= 0,64 m & \\
\multicolumn{4}{|c|}{ ERRO: $\mathbf{4 , 3 4} \%$} \\
\hline
\end{tabular}

Figura 6 - Resultados da Inversão dos dados da SEV 2.

mas variações de resistividade (baixas resistividades em torno de $600 \Omega . m$ ) em pacotes com resistividade elevada (a partir de $1600 \Omega . m)$. Esta informação pode indicar a presença de zonas fraturadas, as quais devem conter água.

\section{Interpretação conjunta dos dados}

Com o objetivo de determinar as variações de resistividade nas seções geoelétricas 2D e associá-las ao fraturamento presente nas rochas, identificaram-se os locais dessas variações (pela posição das estacas dos caminhamentos) e realizou-se a comparação entre esses locais e a presença de fraturas mapeadas a partir das fotografias aéreas.
Na seção de resistividade resultante do caminhamento 1 observam-se três regiões que podem ser caracterizadas como zonas fraturadas com possibilidades de conterem água (devido aos baixos valores de resistividade), caracterizando 0 aqüífero. Próximo a estas regiões foram mapeados traços de fraturas (Figura 9), cujas orientações são apresentadas na Tabela 1.

Nesta seção, observa-se também que as regiões próximas às estacas $300 \mathrm{~m}$ e $810 \mathrm{~m}$ são as que apresentam maior potencial aqüífero, uma vez que a baixa resistividade é bem marcada na seção e se estende em profundidade. É importante ressaltar que os traços de fratura que cruzam essas regiões apresentam orientações N50E/vert, N40E/vert e N50W/vert. 

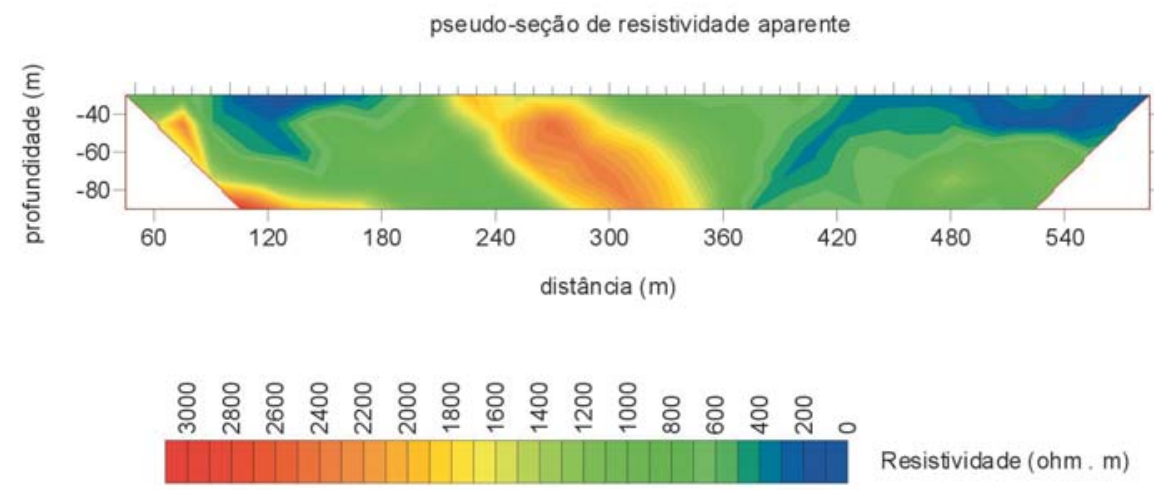

perfil de resistividade gerado pelo modelo de inversão incluindo correção topográfica

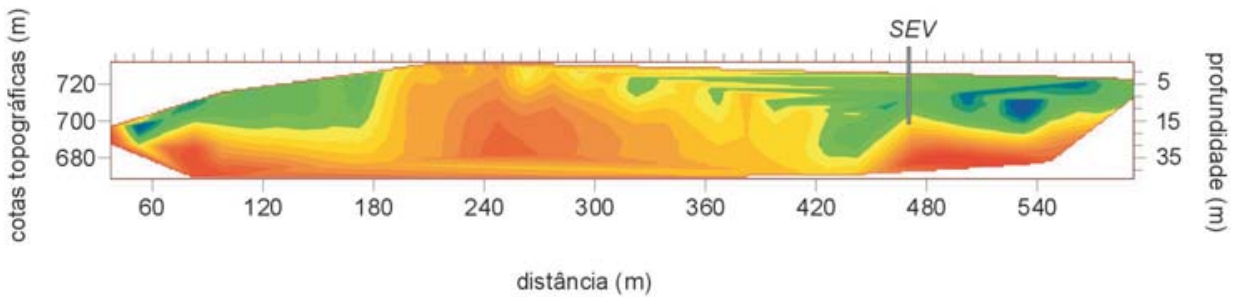

ERRO: $9,3 \%$

Figura 7 - Pseudo-seção de resistividade aparente e perfil de resistividade gerado pelo modelo de inversão.

Tabela 1 - Posições das estacas (CE-1) e direções dos traços de fraturas relacionados aos baixos valores na seção de resistividade.

\begin{tabular}{|c|c|c|}
\hline Posição da estaca $(\mathrm{m})$ & Orientação das fraturas & Direções pré-cambrianas (reativadas) \\
\hline 90 & N50E/vert & $\mathbf{Y}$ \\
\hline 150 e 180 & N20W/vert, N50E/vert & $\mathbf{X}, \mathbf{Y}$ \\
\hline 300 & N50E/vert, N40E/vert e N50W/vert & $\mathbf{Y}, \mathbf{R}$ \\
\hline 810 & N40E/vert & $\mathbf{Y}$ \\
\hline 960 & NS/vert & $\mathbf{X}$ \\
\hline 990 & N70E/vert & $\mathbf{R}$ \\
\hline
\end{tabular}

Na região próxima a estaca 300 , onde foram mapeados traços de fratura orientados segundo N40E/vertical, N50E/vertical e N50W/vertical, ocorre a intersecção de zonas de cisalhamento (interpretadas na imagem ETM-MAG), orientadas segundo N40E e N35W, como observado na Figura 9.

Na seção de resistividade resultante do caminhamento 2 também observam-se regiões que podem ser caracterizadas como zonas fraturadas com possibilidades de conterem água (devido aos baixos valores de resistividade), uma no início da seção e outra nas proximidades da estaca $450 \mathrm{~m}$. Próximo a estas regiões foram interpretados traços de fraturas (Figura 10), cujas orientações são apresentadas na Tabela 2.

Nesta seção (caminhamento 2), a região próxima às estacas $420 \mathrm{~m}$ a $480 \mathrm{~m}$ apresenta baixa resistividade com continuidade em profundidade, 0 que indica o potencial aqǘf́ero das fraturas mapeadas de direção N 65E e N 50W.

Ainda analisando-se 0 caminhamento 2, existem dois poços locados a aproximadamente 60 metros das estacas 180 e 210. Esses poços apresentam baixa produtividade $\left(0,07 \mathrm{~m}^{3} / \mathrm{h} / \mathrm{m}\right.$ e $\left.0,149 \mathrm{~m}^{3} / \mathrm{h} / \mathrm{m}\right)$. A explicação para esta baixa produtividade é evidenciada na seção de resistividade, onde é possível verificar que nas proximidades das estacas 180 e 210 não ocorrem zonas 


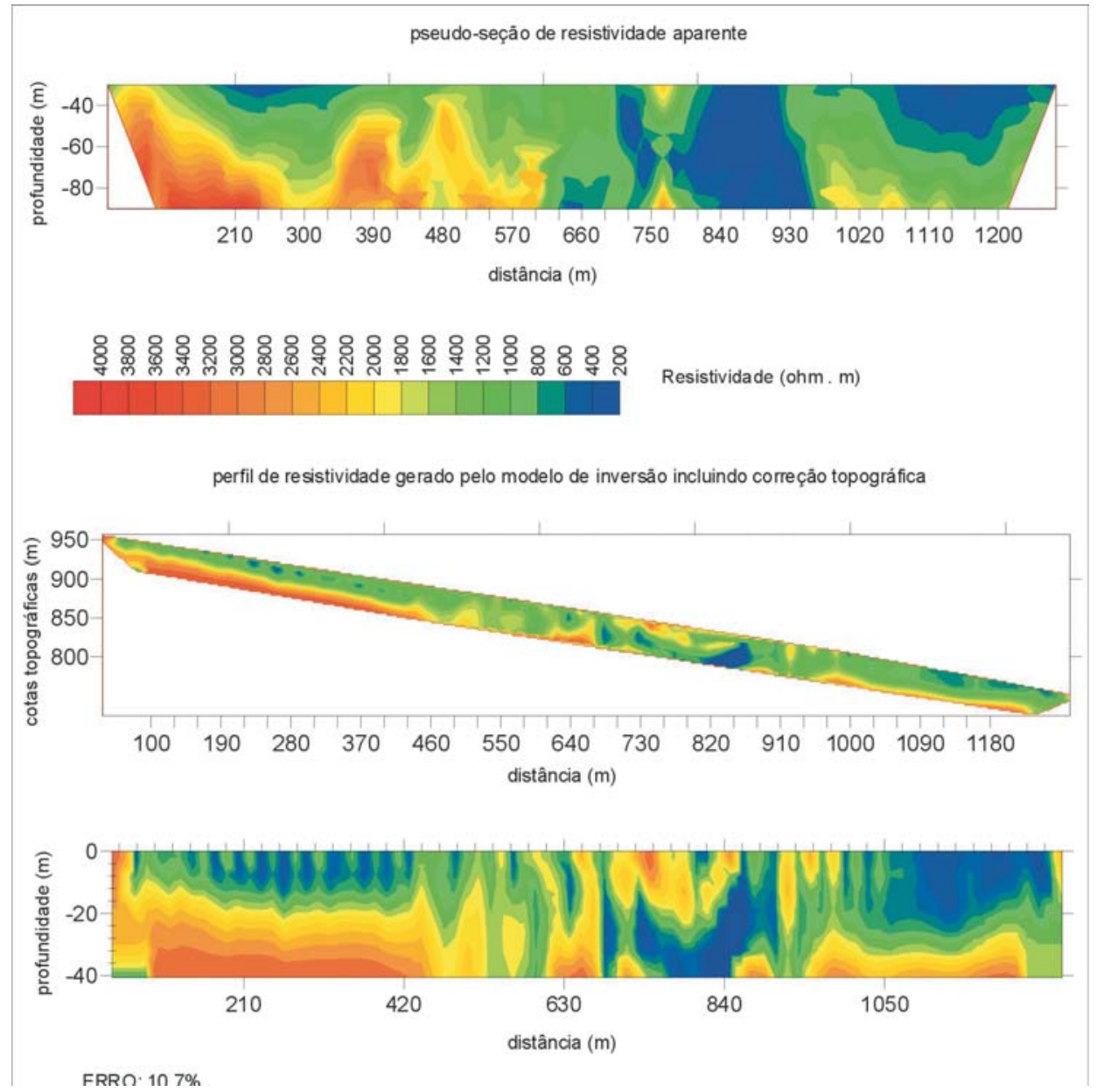

Figura 8 - Pseudo-seção de resistividade aparente e perfil de resistividade gerado pelo modelo de inversão.

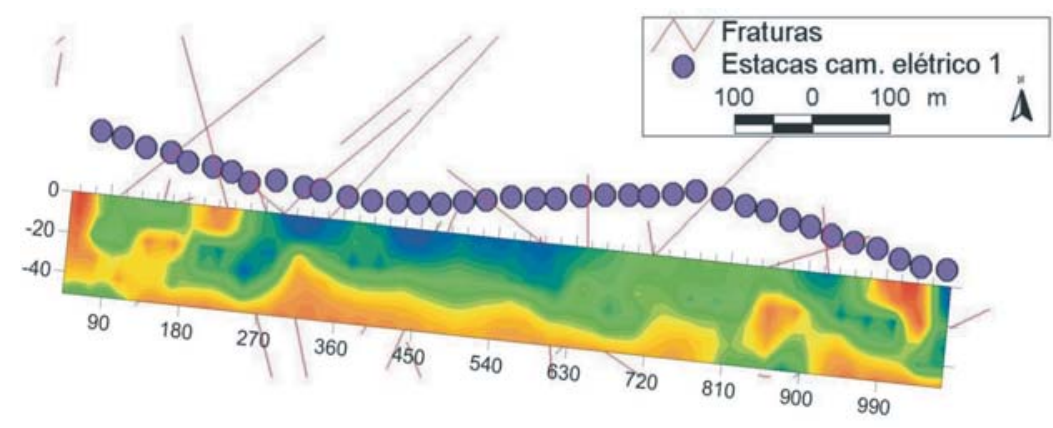

Figura 9 - Fraturas mapeadas e perfil de resistividade. No perfil de resistividade a cor azul representa baixos valores e a cor vermelha representa altos valores de resistividade.

de baixa resistividade que possam indicar zonas fraturadas que contêm água.

A seção referente ao caminhamento 3 apresenta em meio aos altos valores de resistividade característicos de gnaisses (acima de $1.200 \Omega$.m) porções de baixos valores de resistividade (menores que $800 \Omega$.m). Essas regiões de baixas resistividades são indicativas de zonas fraturadas preenchidas por água. A Figura 11 apresenta as fraturas mapeadas e que são interceptadas pelo ca- 


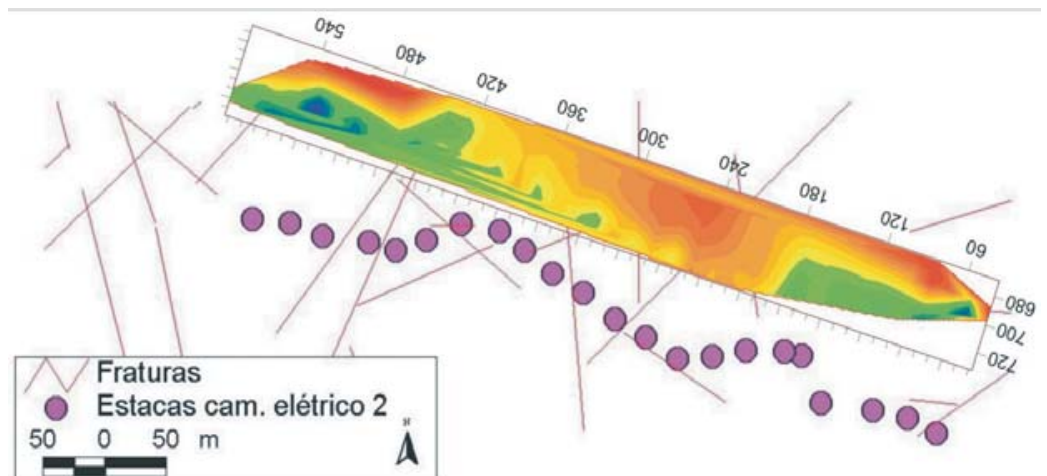

Figura 10 - Fraturas mapeadas e perfil de resistividade. No perfil de resistividade a cor azul representa baixos valores e a cor vermelha representa altos valores de resistividade.

Tabela 2 - Posições das estacas (CE-2) e direções dos traços de fraturas relacionados aos baixos valores na seção de resistividade.

\begin{tabular}{|c|c|c|}
\hline Posição da estaca $(\mathrm{m})$ & Direção das fraturas & Direções pré-cambrianas (reativadas) \\
\hline 30 e 60 & E-W/vert & $\mathbf{T}$ \\
\hline 150 e 180 & N 10W & $\mathbf{X}$ \\
\hline 270 & NS/vert N 45E/vert e N60W/vert & $\mathbf{X}, \mathbf{Y}, \mathbf{R}$ \\
\hline 330 & N 5W/vert e N 45E/vert & $\mathbf{X ~ e ~ Y ~}$ \\
\hline 360 & N 5W/vert e N 65E/vert & $\mathbf{X ~ e ~ R ~}$ \\
\hline 390 & N 65E/vert & $\mathbf{R ~ e ~ R '}$ \\
\hline 420 a 480 & N 65E/vert e N 50W/vert & Y e P \\
\hline 540 e 570 & N 40E/vert e N 25E/vert &
\end{tabular}

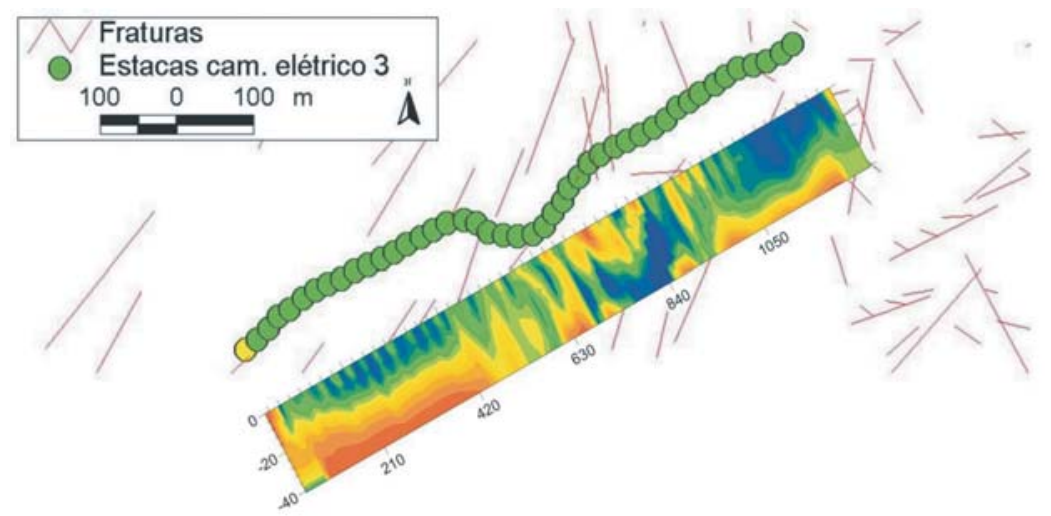

Figura 11 - Fraturas mapeadas e perfil de resistividade. No perfil de resistividade a cor azul representa baixos valores e a cor vermelha representa altos valores de resistividade.

minhamento elétrico. A Tabela 3 apresenta a posição das estacas e as direções das fraturas.

Nas proximidades do caminhamento 3 ocorrem três nascentes. Conforme observado em campo, nesses locais a água mina de fraturas paralelas à foliação (direção NE-SW) de alto mergulho, em gnaisses bandados. Observa-se que o perfil geofísico cruza um traço de fratura mapeado, de orientação NE, nas proximidades das estacas 480-510 0 qual também cruza o local de uma das nascentes, indicando o potencial das fraturas NE-SW para acumulação de água subterrânea. 
Tabela 3 - Posições das estacas (CE-3) e direções dos traços de fraturas relacionados aos baixos valores na seção de resistividade.

\begin{tabular}{|c|c|c|}
\hline Posição da estaca $(\mathrm{m})$ & Direção das fraturas & Direções pré-cambrianas (reativadas) \\
\hline 480 e 510 & N 20E/vert & $\mathbf{P}$ \\
\hline 570 & N 25E/vert & $\mathbf{P}$ \\
\hline 690 a 870 & N 20E/vert, NS/vert e N 10W/vert & $\mathbf{P} \mathbf{X}$ X \\
\hline 900 & NS/vert & $\mathbf{X}$ \\
\hline 1080 e 1110 & N20W/vert & R' e X \\
\hline 1230 & N50W/vert e NS/vert & $\mathbf{X}$ \\
\hline 1260 & NS/vert & \\
\hline
\end{tabular}

Nota-se na seção de resistividade que regiões localizadas nas proximidades das estacas 480-510, 570 e 690-870 apresentam forte indício de serem zonas fraturadas com ocorrência de água, uma vez que os baixos valores de resistividade são coincidentes com as fraturas mapeadas, se estendem em profundidade e são delimitados por regiões de alta resistividade, o que indica que se trata de uma mesma rocha (gnaisse), que possui locais de baixa resistividade em função da maior presença de água nas fraturas. Mais uma vez fica evidente a importância da identificação das fraturas orientadas segundo as direções N20E e NS para a definição de locais mais favoráveis à acumulação e armazenamento de água na área de estudo.

\section{CONCLUSÕES}

0 mapeamento de fraturas a partir de fotografias aéreas auxilia da identificação das regiões mais favoráveis à infiltração, circulação e armazenamento de água em aqüífero cristalino e na determinação das direções dos perfis elétricos, otimizando tempo e custos.

0 resultado da inversão dos dados geofísicos que utiliza os dados de poços e verificações de campo de modo a ajustar o modelo geofísico aos dados geológicos, tornando-o mais próximo da realidade, aliado ao mapeamento de fraturas, confirmou a grande importância das fraturas verticais de direção N45E, N2OE e N60E (paralelas à foliação das rochas) e secundariamente das fraturas verticais de direção N60W e N10W para a prospecção de água subterrânea na região. Observou-se também que, em alguns locais, as fraturas mapeadas em escala de maior detalhe, coincidem com as direções das zonas de cisalhamento mapeadas em escala regional. 0 resultado das interpretações mostrou a pequena espessura de solo e manto de intemperismo na área, demonstrando a pequena influência destes nos processos hidrogeológicos da área, sendo as fraturas de direção N45E, N20E e
N60E os principais condicionantes hidrogeológicos para a região de Lindóia.

Dessa forma, a análise integrada do mapeamento de fraturas, de dados geofísicos invertidos e de dados geológicos de campo se mostraram uma importante ferramenta no estudo de aqǘferos cristalinos, pois permitem a identificcação das fraturas preenchidas por água, representada por baixas respostas de resistividade nas proximidades de fraturas previamente mapeadas. Assim é possível associar as respostas do levantamento geofísico com as direções de fraturas, otimizar os levantamentos geofísicos de campo e auxiliar o entendimento do aqǘfero fraturado e conseqüentemente proporcionar a identificação de locais mais favoráveis à locação de poços tubulares profundos.

\section{AGRADECIMENTOS}

Os autores agradecem a FAPESP pelo suporte financeiro (00/05740-2) e ao Instituto de Geociências e ao CEPAS (Centro de Pesquisa de Águas Subterrâneas) da Universidade de São Paulo pelo suporte técnico.

\section{REFERÊNCIAS}

BONHAM-CARTER GF. 1994. Geographic Information Systems for Geoscientists - Modelling with GIS. 1. ed. Ontario, Pergamon, 398 p.

CARRUTHERS RM \& SMITH IF. 1992. The use of ground electrical survey methods for siting water-supply boreholes in shallow crystalline basement terrains. In: Hydrogeology of crystalline basement aquifers in Africa. WRIGHT E.P \& BURGESS W.G (Eds). Geological Society Special publication, 66: 203-220.

CPRM. 2002. Atlas geoambiental das bacias hidrográficas dos rios Mogi Guaçu e Pardo (SP). CD-ROM.

EDWARDS LS. 1977. A modified pseudo-section for resistivity and induced polarization. Geophysics, 3: 78-95. 
FOX RC, HOHMANN GW, KILLPACK TJ \& RIJO L. 1980. Topographic effects in resistivity and induced polarization surveys. Geophysics, 45: 75-93.

GALLAS JDF. 2000. Principais métodos geoelétricos e suas aplicações em prospecção mineral, hidrogeologia, geologia de engenharia e geologia ambiental. Tese de doutoramento. Rio Claro - UNESP, 174 p.

GALLAS JDF. 2003. Prospecção de água subterrânea em aqüíferos cristalinos com 0 emprego de métodos indiretos. Revista do Instituto Geológico, 24(1/2): 43-51.

GEOTOMO SOFTWARE. 2003. RES2DINV: Rapid 2-D Resistivity \& IP inversion using the least-squares method, vers. 3.4.

GROOT-HEDLIN C. \& CONSTABLE S. 1990. Occam's inversion to generate smooth, two-dimensional models form magnetotelluric data. Geophysics, 55: 1613-1624.

HAZELL JRT, CRATCHLEY CR \& JONES CRC. 1992. The hydrogeology of crystalline aquifers in northern Nigeria and geophysical techniques used in their exploration. In: Hydrogeology of crystalline basement aquifers in Africa. WRIGHT EP \& BURGESS WG (Eds.). Geological Society Special publication, 66: 155-182.

KELLER GV \& FRISCHKNECHT FC. 1977. Electrical Methods in Geophysical Prospecting. Oxford, Pergamon Press, 517 p.

LOKE MH \& BARKER RD. 1996. Rapid least-squares inversion of apparent resistivity pseudosections by a quasi-Newton method. Geophysical Prospecting, 44: 131-152.

MADRUCCI V. 2004. Prospecção de água subterrânea em terreno cristalino utilizando-se análise integrada de dados de sensoriamento remoto, geofísicos e técnicas de geoprocessamento, região de Lindóia, SP. Tese de doutoramento. São Paulo - USP, 226 p.

MADRUCCI V, ARAÚJO CC \& TAIOLI F. 2003. Sensoriamento remoto aerogeofísica e geoprocessamento aplicados ao estudo de aqüífero fra- turado em terreno cristalino, leste do Estado de São Paulo. Revista Brasileira de Geociências, 33(2 supl): 43-52.

MADRUCCI V \& TAIOLI F. 2004. Groundwater favorability map using multicriteria data analysis on crystalline terrain, São Paulo State, Brazil. 32 International Geological Congress, Abstracts - CD-ROM.

ORELLANA E. 1972. Prospeccion geoeletrica en corriente continua. Madrid, Paraninfo, $523 \mathrm{p}$.

PALACKY GJ \& KADEKARU K. 1979. Effect of tropical weathering on electrical and electromagnetic measurements. Geophysics, 44(1): 69-88.

PELTON WH, RIJO L \& SWIFT Jr. CM. 1978. Inversion of twodimensional Resistivity and Induced Polarization Data. Geophysics, Tulsa - Estados Unidos, 43: 788-803.

SASAKI Y. 1992. Resolution of resistivity tomography inferred from numerical simulation. Geophysical Prospecting, 40: 453-464.

SOARES PC \& FIORI AP. 1976. Lógica e Sistemática na análise e interpretação de fotografias aéreas em geologia. Noticiário Geomorfológico, 16: 107-121.

TELFORD WM, GELDART LP \& SHERIFF RE. 1990. Applied geophysics. Sec. Edition, Cambridge, Cambridge University Press, 770 p.

VOUILLAMOZ JM, LEGCHENKO A, ALBOY Y, BAKALOWICS M, BALTASSAT JM \& AL-FARES W. 2003. Localization and satured karst aquifer with magnetic resonance sounding and resistivity imagery. Ground Water, 41(5): 578-586.

YOSHINAGA S. 1990. Estudos hidrogeológicos, hidrogeoquímicos e isotópicos das águas minerais e termais de Águas de Lindóia e Lindóia, SP. Dissertação de Mestrado. São Paulo - USP, 113 p.

\section{NOTAS SOBRE OS AUTORES}

Vanessa Madrucci. Formou-se em geologia pela UNESP em 1996. Mestre em Sensoriamento Remoto pelo INPE em 1999 e Doutora em Geociências pelo Instituto de Geociências da USP em 2004. Exerceu 0 cargo de Pesquisador Científico no Instituto Geológico (Secretaria de Meio Ambiente - SP) até Janeiro de 2005 quando se transferiu para o Serviço Municipal de Saneamento Ambiental de Santo André (SEMASA) exercendo a função de coordenadora de programas até julho de 2005. Atualmente trabalha no CENTRAN (centro de excelência em engenharia de transportes). Sua área de interesse é sensoriamento remoto, geoprocessamento e geofísica aplicados à hidrogeologia. É membro da SBG

Fabio Taioli. Formou-se em Geologia pela USP em 1973. Trabalhou como geofísico da Petrobras até 1975 quando se transferiu para o Instituto de Pesquisas Tecnológicas do Estado de São Paulo - IPT. MSc em Mining Engineering pela The Pennsylvania State University na área de Geomecânica em 1987. Doutor pelo Instituto de Geociências da USP em 1992 na área de Geofísica Aplicada. Ingressou no IG-USP em 1995, tornando-se Livre-Docente (Associado) em 1999. Sua área de interesse é a aplicação de métodos geofísicos a problemas de engenharia civil e de minas e meio ambiente. É membro da SBGf, SEG, EEGS, ISRM, ABGE, IAEG, ABMS e CBMR.

Carlos César de Araújo. Formou-se em geologia pela USP em 1996. Mestre em Recursos Minerais pela USP em 1999 e Doutor em Geologia Sedimentar pela USP em 2003. Atualmente trabalha na Área de Negócio Internacional da Petrobras. Tem interesse em geoprocessamento, geologia do petróleo e caracterização de reservatórios. É membro da SBG. 